ical Research (LTER) studies $(14,23,27,28)$ comparing $\mathrm{C}$ cycling and community attributes in upland and lowland sites (table S2) are consistent with the responses to rainfall variability reported in this 4-year experiment. Thus, reduced soil $\mathrm{C}$ storage and trace gas fluxes, reduced dominance by productive $\mathrm{C}_{4}$ grasses, and a more diverse and xeric flora, all characteristic of upland sites (14), can be forecast as longer-term and more widespread responses to chronic increases in rainfall variability in this mesic grassland.

Our results have several implications for predicting the magnitude and direction of change in grasslands under future climates. First, it is clear that species, community, and ecosystem responses to alterations in storm frequency and intensity can be rapid and independent of changes in annual precipitation amount. Increased temporal variability in precipitation patterns and soil moisture in grasslands will, in the short term, increase plant water stress and alter key $\mathrm{C}$ cycling processes such as net photosynthesis, aboveground productivity, and soil $\mathrm{CO}_{2}$ flux, with long-term consequences for $\mathrm{C}$ storage and biotic-atmospheric feedbacks. Shifts in plant species composition toward more diverse communities and toward communities characteristic of more xeric environments are also expected, further lowering productivity without a change in mean rainfall quantity. Second, future climates are predicted to include changes both in precipitation variability and in quantity $(1,5,7,10)$. Thus, projected ecosystem responses to wetter or drier rainfall regimes must account for concomitant changes in storm frequency and size (10). In this study, responses to increased rainfall variability were greatest in the driest years, suggesting that greater impacts will occur in concert with drought or in more arid systems. Finally, $90 \%$ of all terrestrial vegetation types worldwide have $>50 \%$ of their roots in the upper $0.3 \mathrm{~m}$ of the soil profile (19, 20). Consequently, most biomes are at risk of being affected by projected increases in rainfall variability and more extreme soil moisture dynamics, independent of changes in precipitation quantity.

References and Notes

1. Intergovernmental Panel on Climate Change, Climate Change 2001: Synthesis Report, Third Assessment Report of the Intergovernmental Panel on Climate Change (Cambridge Univ. Press, New York, 2001).

2. D. Rind, R. Goldberg, R. Ruedy, Clim. Change 14, 5 (1989).

3. L. O. Mearns, S. H. Schneider, S. L. Thompson, L. R. McDaniel, J. Geophys. Res. 95, 20469 (1990).

4. H. B. Gordon, P. H. Whetton, A. B. Pittock, A. M. Fowler, M. R. Haylock, Clim. Dyn. 8, 83 (1992).

5. D. R. Easterling et al., Science 289, 2068 (2000).

6. T. R. Karl, R. W. Knight, N. Plummer, Nature $\mathbf{3 7 7}, 217$ (1995).

7. P. Y. Groisman et al., Clim. Change 42, 243 (1999).

8. N. Plummer et al., Clim. Change 42, 183 (1999).

9. D. M. Gates, Climate Change and Its Biological Consequences (Sinauer, Sunderland, MA, 1993).

10. L. O. Mearns, C. Rosenzweig, R. Goldberg, Clim. Change 35, 367 (1997).
11. G. W. Koch, H. A. Mooney, Carbon Dioxide and Terrestrial Ecosystems (Academic Press, New York, 1996).

12. R. W. Katz, B. G. Brown, Clim. Change 21, 289 (1992).

13. C. Parmesan, T. L. Root, M. R. Willig, Bull. Am. Meteorol. Soc. 81, 443 (2000).

14. A. K. Knapp, J. M. Briggs, D. C. Hartnett, S. L. Collins, Grassland Dynamics: Long-Term Ecological Research in Tallgrass Prairie (Oxford Univ. Press, New York, 1998).

15. A. K. Knapp, M. D. Smith, Science 291, 481 (2001).

16. W. H. Schlesinger, Biogeochemistry: An Analysis of Global Change (Academic Press, New York, 1997).

17. Materials and methods are available as supporting material on Science Online.

18. P. A. Fay, J. D. Carlisle, A. K. Knapp, J. M. Blair, S. L. Collins, Ecosystems 3, 308 (2000)

19. R. B. Jackson et al., Oecologia 108, 389 (1996).

20. J. J. Schenk, R. B. Jackson, Ecol. Monogr. 72, 311 (2002).

21. J. A. Ludwig, J. F. Reynolds, Statistical Ecology (Wiley, New York, 1988).
22. Y. S. Luo, S. Wan, D. Hui, L. L. Wallace, Nature 413 , 622 (2001).

23. A. K. Knapp, S. L. Conard, J. M. Blair, Ecol. Appl. 8, 760 (1998).

24. L. C. Johnson, J. R. Matchett, Ecology 82, 3377 (2001).

25. R. E. Ricklefs, Am. Nat. 111, 376 (1977).

26. R. B. Waide et al., Annu. Rev. Ecol. Syst. 30, 257 (1999).

27. D. S. Schimel et al., Ecology 72, 672 (1991)

28. A. K. Knapp et al., Ecology 74, 549 (1993).

29. We thank P. Reich and R. Jackson for providing valuable comments on an earlier version of this manuscript. Supported by USDA Ecosystems, U.S. Department of Energy National Institute for Global Environmental Change and the NSF LTER programs, and the Nature Conservancy.

Supporting Online Material

www.sciencemag.org/cgi/content/full/298/5601/22202/ DC1

Materials and Methods

Tables S1 and S2

19 July 2002; accepted 21 October 2002

\title{
Small Nuclear Ribonucleoprotein Remodeling During Catalytic Activation of the Spliceosome
}

\author{
Evgeny M. Makarov, ${ }^{1}$ Olga V. Makarova, ${ }^{1}$ Henning Urlaub, ${ }^{1}$ \\ Marc Gentzel, ${ }^{2}$ Cindy L. Will, ${ }^{1}$ Matthias Wilm, ${ }^{2}$ \\ Reinhard Lührmann ${ }^{1 *}$
}

\begin{abstract}
Major structural changes occur in the spliceosome during its activation just before catalyzing the splicing of pre-messenger RNAs (pre-mRNAs). Whereas changes in small nuclear RNA (snRNA) conformation are well documented, little is known about remodeling of small nuclear ribonucleoprotein (snRNP) structures during spliceosome activation. Here, human $45 \mathrm{~S}$ activated spliceosomes and a previously unknown $35 S$ U5 snRNP were isolated by immunoaffinity selection and were characterized by mass spectrometry. Comparison of their protein components with those of other snRNP and spliceosomal complexes revealed a major change in protein composition during spliceosome activation. Our data also suggest that the U5 snRNP is dramatically remodeled at this stage, with the Prp19 complex and other factors tightly associating, possibly in exchange for other U5 proteins, and suggest that after catalysis the remodeled $\mathrm{U} 5$ is eventually released from the postsplicing complex as a $35 S$ snRNP particle.
\end{abstract}

Pre-mRNA splicing, the removal of introns from mRNA precursors, is a prerequisite for the expression of most eukaryotic genes. Catalysis of the two transesterification steps of the premRNA splicing reaction takes place in the spliceosome, an elaborate molecular machine formed by the ordered interaction of four small nuclear ribonucleoproteins (snRNPs), U1, U2, $\mathrm{U} 5$, and U4/U6, and numerous splicing factors with the pre-mRNA (1). Spliceosome assembly is initiated by the interaction of the $\mathrm{U} 1$ and $\mathrm{U} 2$ snRNPs with the pre-mRNA 5' splice site and

${ }^{1}$ Department of Cellular Biochemistry, Max Planck Institute of Biophysical Chemistry, D-37077 Göttingen, Germany. ${ }^{2}$ European Molecular Biology Laboratory, Bioanalytical Research Group, D-69117 Heidelberg, Germany.

*To whom correspondence should be addressed. Email: reinhard.luehrmann@mpi-bpc.mpg.de branch site, respectively, generating the prespliceosome or complex A. This complex then recruits the pre-formed U4/U6.U5 tri-snRNP, in which the U4 and U6 snRNAs are base paired, to form the mature spliceosome or complex B. Conversion of the mature spliceosome into a machine capable of catalyzing splicing (hereafter termed the activated spliceosome) entails a major structural change that results in the dissociation of the U1 and U4 snRNPs. Subsequently, the activated spliceosome catalyzes the first transesterification step of splicing and complex $\mathrm{C}$ is formed. After the second step of splicing, the mRNA is released and the postspliceosomal complex, containing the excised intron and the U2, U5 and, U6 snRNPs, disassembles and the snRNPs are then recycled for new rounds of splicing.

The spliceosome is, thus, a highly dynamic molecular machine whose composition is not 
static and whose structure undergoes multiple rearrangements during each cycle of splicing. The most dramatic and functionally decisive remodeling step occurs during the transformation of complex B to the activated spliceosome. During this step, base pairing of the U1 and U4 snRNAs with the 5 'splice site and U6 snRNA, respectively, is disrupted, allowing U6 bases to pair with both the U2 snRNA and the $5^{\prime}$ end of the intron. Whereas remodeling events involving the snRNAs have been investigated intensively, little is known about changes in snRNP structure and protein composition during spliceosome activation. However, this information is of utmost importance to understand the nature of the catalytic RNP core of the spliceosome. A comparative analysis of the protein composition of purified splicing complexes A, B, and C was previously carried out by two-dimensional (2D) gel electrophoresis, providing initial insight into the complex and dynamic composition of the spliceosome $(2,3)$. More recently, mass spectrometry has revealed more than 200 proteins present in a mixture of spliceosomal complexes $(4,5)$. However, to date, the protein composition of splicing complexes at a defined assembly or functional stage has only been determined by mass spectrometry for complex $\mathrm{C} \mathrm{(6)}$.

With the aim of purifying activated spliceosomes, we first raised antibodies to peptides against the splicing factor SKIP (Ski oncogene interacting protein) (7), which is neither stably associated with U4/U6.U5 tri-snRNPs nor present in purified pre-spliceosomes (8) and is thus likely to be recruited to the spliceosome at a later stage of its assembly. Affinity-purified antibodies to SKIP reacted specifically with a protein of expected molecular weight in nuclear extract on immunoblots (not shown) and precipitated splicing complexes from an in vitro splicing reaction with high efficiency (Fig. 1A). Efficient precipitation of unspliced pre-mRNA was first observed after a 10-min incubation and, at later time points, splicing intermediates and excised intron (but only very low levels of spliced product) were precipitated. Thus, SKIP is recruited to the spliceosome before the first catalytic step of splicing, remains bound through both catalytic steps, and ultimately associates with the spliced-out intron.

To isolate splicing complexes that had not yet undergone the first catalytic step of splicing (and thus potentially represent activated spliceosomes), we immunoaffinity-selected complexes formed after $10 \mathrm{~min}$ of splicing with antibodies to SKIP. Bound complexes were eluted under native conditions with antigenic SKIP peptide, and their RNA composition was analyzed by denaturing polyacrylamide gel electrophoresis (PAGE) (Fig. 1B). The affinity-purified complexes contained equimolar amounts of unspliced pre-mRNA and U2, U5, and U6 snRNA,
A

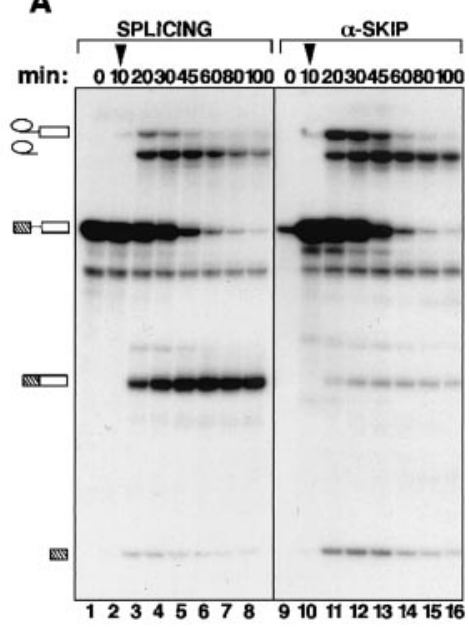

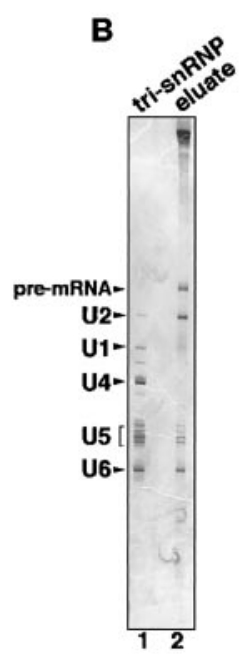

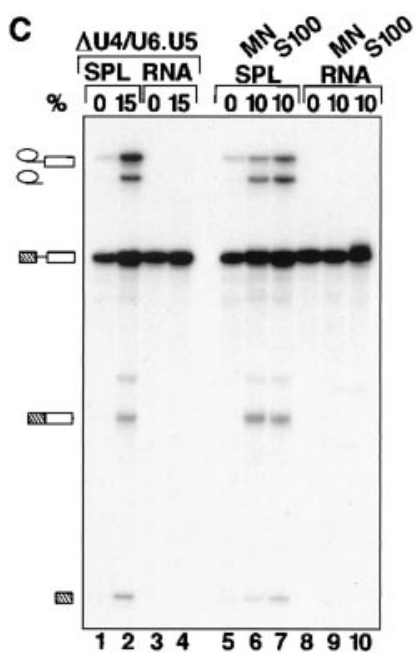

Fig. 1. Immunoaffinity selection of functional, activated spliceosomes. (A) Antibodies to SKIP efficiently precipitate spliceosomal complexes. In vitro splicing of ${ }^{32} \mathrm{P}$-labeled MINX pre-mRNA (derived from the adenovirus major late transcription unit) was performed for the indicated times, and radiolabeled RNA was analyzed by denaturing PAGE either directly after splicing (lanes 1 to 8 ) or after subsequent immunoprecipitation with antibodies to SKIP (lanes 9 to 16) (10). The positions of the first-step intron- $3^{\prime}$ exon intermediate, spliced-out intron, pre-mRNA, spliced mRNA, and first-step $5^{\prime}$ exon intermediate are indicated from top to bottom on the left. (B) RNA content of complexes affinity-selected after $10 \mathrm{~min}$ of splicing with antibodies to SKIP and eluted with competing SKIP peptide (lane 2). RNA was analyzed by denaturing PAGE and visualized by silver staining. Lane 1, snRNA marker from U4/U6.U5 tri-snRNPs. (C) Affinity-selected, activated spliceosomes catalyze splicing in the absence of exogenously added snRNPs. Splicing complexes affinity-selected with antibodies to SKIP (SPL) or naked ${ }^{32}$ P-labeled premRNA (RNA) were incubated for 40 min under splicing conditions in the absence of nuclear extract (lanes $1,3,5$, and 8 ) or in the presence of $15 \%$ nuclear extract from which the $U 4, U 5$ and $U 6$ snRNAs had been removed by oligonucleotide-directed ribonuclease (RNase) $\mathrm{H}$ digestion (lanes 2 and 4), 10\% micrococcal nuclease treated extract (MN, lanes 6 and 9), or 10\% S100 cytosolic extract (S100, lanes 7 and 10). RNA was analyzed as above.

but U1 and U4 were largely absent (lane 2). These results indicate that predominantly activated spliceosomes, as opposed to spliceosomal complex B, had been isolated. Thus, SKIP appears to first bind precisely at the time of spliceosome activation, allowing for the isolation of a spliceosome assembly intermediate that is formed after complex B, but before complex C. We refer to this previously unknown complex as $\mathrm{B}^{*}$.

In the presence of nuclear extract that was depleted of U4/U6.U5 tri-snRNPs (Fig. 1C, lane 2), treated with micrococcal nuclease (lane 6) or in the presence of cytosolic S100 (lane 7), the affinity-selected spliceosomes catalyzed both the first and second steps of splicing, but naked pre-mRNA (lanes 4, 9, and 10) did not. Thus, these experiments demonstrate the functional integrity of the affinity-purified complexes and support their designation as activated spliceosomes; that is, their catalytic activity does not require complementation with U4/U6.U5 tri-snRNPs or with the U1 and U4 snRNPs that they lack.

To characterize the affinity-purifed $\mathrm{B}^{*}$ complex in more detail, we subjected it to glycerol gradient centrifugation and analyzed the distribution of the pre-mRNA and snRNAs across the gradient by denaturing PAGE. Complexes containing equimolar amounts of $\mathrm{U} 2, \mathrm{U} 5$, and $\mathrm{U} 6$ in addition to pre-mRNA (i.e, activated spliceosomes) peaked in the $45 S$ region of the gradient (Fig. 2A, top). In addition, low amounts of a $35 \mathrm{~S}$ particle containing U5 snRNA were observed. The latter particle is not generated by dissociation of the $45 \mathrm{~S}$ activated spliceosome during gradient centrifugation; when the anti-SKIP eluate was subsequently affinity-selected with antibodies to peptide against the U2 snRNP-specific protein SF3a66 and then subjected to gradient centrifugation, no $35 S$ complex was observed (Fig. 2A, middle). Thus, the $35 S$ complex is likely present in nuclear extract and copurifies with the activated spliceosomes during affinity-selection. Indeed, when an antiSKIP immunoaffinity-selection was performed with nuclear extract (incubated under splicing conditions but in the absence of exogenously added pre-mRNA), the peptide eluate consisted predominantly of $35 \mathrm{~S}$ complexes containing U5 snRNA (Fig. 2A, bottom). Until now, the only known RNP containing exclusively U5 snRNA was the well-defined $20 S$ U5 $\operatorname{snRNP}(9)$. The $35 S$ particle, which contains the SKIP protein, is therefore a previously unknown form of the U5 snRNP. Interestingly, a U2 snRNP complex with an $S$-value of approximately 25 whose precise identity is presently not known, is also observed after each affinity-selection (Fig. 2A).

To determine the polypeptide composition of the $\mathrm{B}^{*}$ complex and $35 S \mathrm{U} 5 \mathrm{snRNP}$, proteins from each affinity-selected complex were separated by gel electrophoresis (Fig. 2, B and C) and characterized by mass spectrometry (Fig. 3) (10). More than 100 proteins were identified in 


\section{R E P O R T S}

the $45 S$ activated spliceosome, 80 of which are known splicing factors. Several of the remaining proteins have domains characteristic of splicing factors, making them good candidates for bona fide spliceosomal proteins. Non-snRNP proteins present in the activated spliceosome include (among others) SKIP, three cyclophilins, the RNA helicases Prp22 and p68, as well as a number of proteins known to be present in the yeast and/or human Prp19 complex (11-13). Thus, these factors are recruited to the spliceosome before catalytic step I and might also function during spliceosome activation.

The protein composition of the $\mathrm{B}^{*}$ complex is clearly distinct from that of the recently purified $\mathrm{C}$ complex $(6,10)$. For example, the activated spliceosome lacks a number of proteins present in complex $\mathrm{C}$, including several step II splicing factors (with the exception of Prp22) and proteins of the exon junction complex (14, 15). Thus, these proteins are stably recruited to the spliceosome concomitant with or after step I of splicing. Surprisingly, about 20 non-snRNP proteins cofractionating with the activated spliceosome are not found in the purified $\mathrm{C}$ complex. Though some differences in protein composition may be due to differences in the procedures used for purification and mass spectrometry, several of these proteins potentially interact transiently with the activated spliceosome and may play a role before step I of splicing.

The activated spliceosome's protein complement also appears to be distinct from that of complex B. Although a comprehensive protein inventory of the latter complex has not yet been determined by mass spectrometry, previous biochemical analyses support the current assumption that most, if not all, U1, U2, and U4/U6.U5 tri-snRNP proteins, are present in complex B $(2,3)$. Consistent with the absence of U1 snRNA, no U1-specific proteins were found in the activated spliceosome. Although all core $17 S \mathrm{U} 2$ proteins (i.e., all SF3a/b subunits, $\mathrm{A}^{\prime}$ and $\mathrm{B}^{\prime \prime}$ ) were present (16), many other U2-associated proteins that were also present in purified complex A (8) were not found. A dramatic loss in tri-snRNP proteins, which appears to accompany the dissociation of U4 from U6 RNA during spliceosome activation, was also observed; all U4/U6 snRNPspecific proteins, most of the LSm proteins, and two tri-snRNP-specific proteins were not present in the activated spliceosome. However, LSm proteins are difficult to detect by mass spectrometry due to the paucity of tryptic fragments obtained and, for this reason, they may simply have escaped detection. Two U5-specific proteins, i.e., $15 \mathrm{~K}$ and $100 \mathrm{~K}$ (hPrp28) which are normally present in $20 S$ U5 and $25 S$ U4/ U6.U5 tri-snRNPs, were also absent. Thus, a major change in the protein composition of the spliceosome occurs at the time of its activation.

Mass spectrometry analysis of the $35 S$ U5 complex (Fig. 3; table S1) revealed striking similarities between its protein composition and that of the $\mathrm{B}^{*}$ complex. For example, both complexes lack the U5-specific $15 \mathrm{~K}$ and $100 \mathrm{~K}$ proteins. Furthermore, the majority of proteins found in the $35 S$ U5 snRNP are also present in the $45 S \mathrm{~B}^{*}$ complex. This suggests that the $35 S$ particle is either a precursor or product of the activated spliceosome. Several observations, however, support the latter conclusion. First, the $35 S$ U5 snRNP particle has a protein complement fundamentally different from that of the smaller 20S U5 particle known to enter the splicing cycle as part of the $25 S$ U4/U6.U5 tri-snRNP (Fig. 3). It also differs markedly from the recently described Saccharomyces cerevisiae penta-snRNP, a large, preassembled snRNP complex containing U1, U2, U4/U6, and U5, which binds as such to the pre-mRNA during spliceosome assembly (17). The pentasnRNP, in contrast to the human $35 S$ snRNP, contains a full complement of the yeast U5, U4/U6, and tri-snRNP proteins. Second, three $35 S$ U5 proteins not present in the $\mathrm{B}^{*}$ complex (i.e., the second step factor hPrp17, the RNA helicase DDX35, and HSP73) are found in complex C (table S1) (5), suggesting that they associate with U5 subsequent to spliceosome activation. Taken together, these results support the idea that the $35 S$ U5 snRNP is generated upon dissociation of the spliceosome after catalysis. Indeed, in initial studies doubly affinitypurified $\mathrm{B}^{*}$ complexes, when incubated under splicing conditions in microccocal nucleasetreated nuclear extract, generate $35 \mathrm{~S}$ U5 snRNPs, confirming their precursor-product relation (not shown).

Because SKIP remains associated with the excised intron (Fig. 1A), the $35 S$ U5 snRNP likely is initially released, together with the U2 and U6 snRNP, as part of the post-splicing intron-containing complex. Mass spectrometry analysis of the protein composition of the latter complex should help clarify this point; however, attempts to purify the excised intron complex in amounts sufficient to carry out mass spectrometry have not, to date, been successful. Gould and co-workers (12) recently isolated a large complex from both $S$. cerevisiae and Saccharomyces pombe that contained solely U2, U5, and U6 snRNPs, making it a good candidate for a spliced-out intron complex; whether it contains excised intron or other splicing products or intermediates is, however, not yet clear. The protein composition of this complex exhibits striking similarities with that of the human $35 S$ U5 snRNP (table S1), suggesting a relation between the two. Most importantly, the yeast orthologs of the three U5-specific proteins and the other proteins of the tri-snRNP that are absent in the $35 \mathrm{~S}$ human complex are also missing in the yeast U2/U5/U6 complex. Thus, this observation is consistent with the idea that the human $35 S$ U5 snRNP may be a dissociation product of a larger postsplicing, intron-containing complex.
A

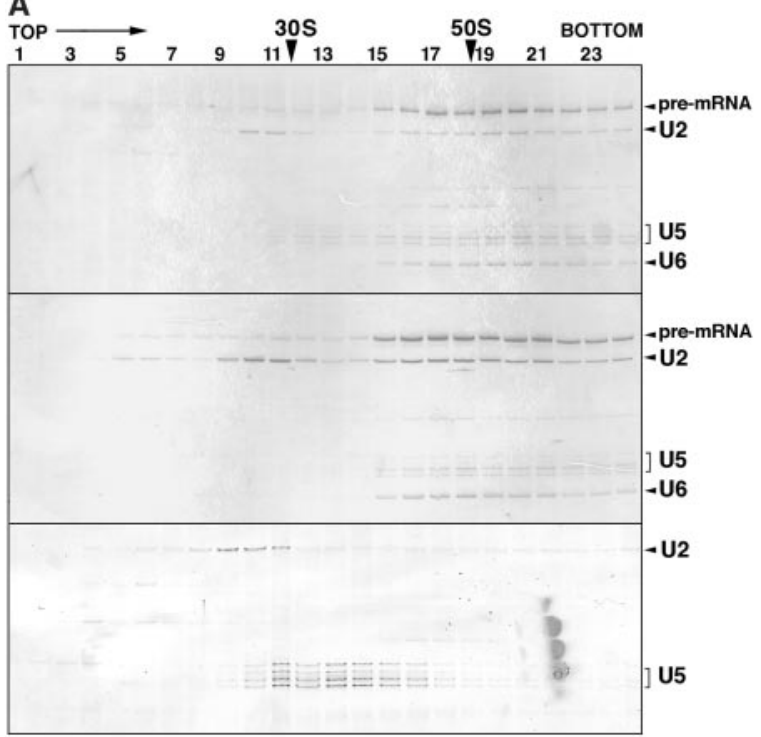

B

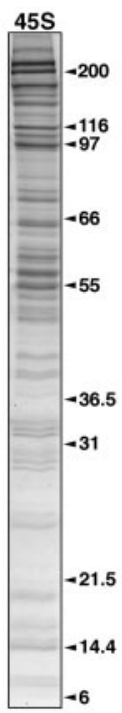

C

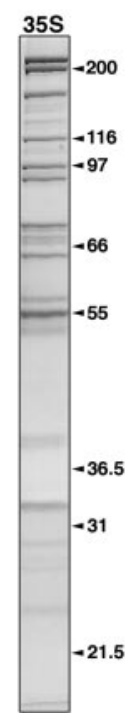

Fig. 2. Sedimentation behavior and protein composition of the activated spliceosome and a previously unknown 35 S U5 snRNP. (A) Complexes were subjected to 10 to $30 \%$ glycerol gradient centrifugation, and RNA from each fraction was analyzed by denaturing PAGE and stained with silver. (Top) Activated spliceosomes affinity-selected with antibodies to SKIP from nuclear extract. (Middle) Activated spliceosomes (isolated as above) subjected to a second immunoaffinity selection with antibodies to SF3a66. (Bottom) Complexes isolated from nuclear extract with antibodies to SKIP without addition of pre-mRNA. In the case of the $35 S$ U5 snRNP, the material for RNA analysis was pooled from three individual gradients. The RNA species, indicated on the right, were identified by Northern hybridization or, in the case of the pre-mRNA, by autoradiography (data not shown). The position of $30 \mathrm{~S}$ and $50 \mathrm{~S}$ ribosomes, run in parallel, is shown at the top. Protein content of the gradient-fractionated $45 S$ spliceosomes (B) or 35 S U5 snRNPs (C). Protein was analyzed by SDS-PAGE and visualized by staining with silver (B) or Coomasie (C). Molecular weight markers are indicated on the right. 


\section{R E P O R T S}

Figure 4 shows a model of the spliceosome assembly-disassembly pathway, highlighting the spliceosome and snRNP remodeling steps

for which we have provided experimental evidence here. The tri-snRNP and additional proteins are recruited to complex A to form com-

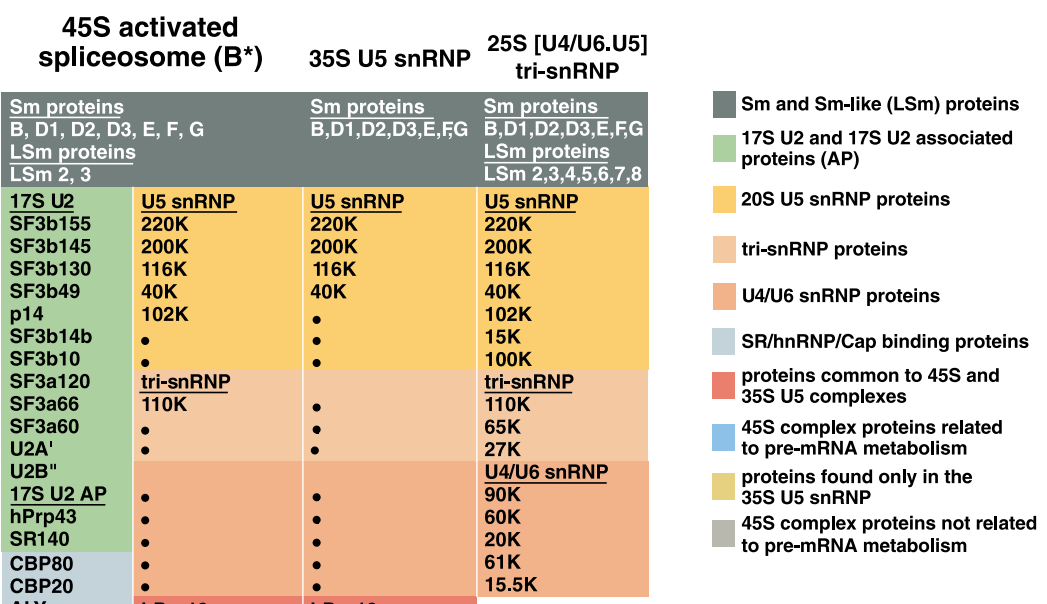

Fig. 3. Protein composition of the activated $45 \mathrm{~S}$ spliceosome and the $35 S$ U5 snRNP. Proteins were identified by mass spectrometry and grouped as indicated. Ribosomal proteins and translation initiation factors that copurify with the activated spliceosome are not listed (table S1). A dot indicates the absence of a given protein.

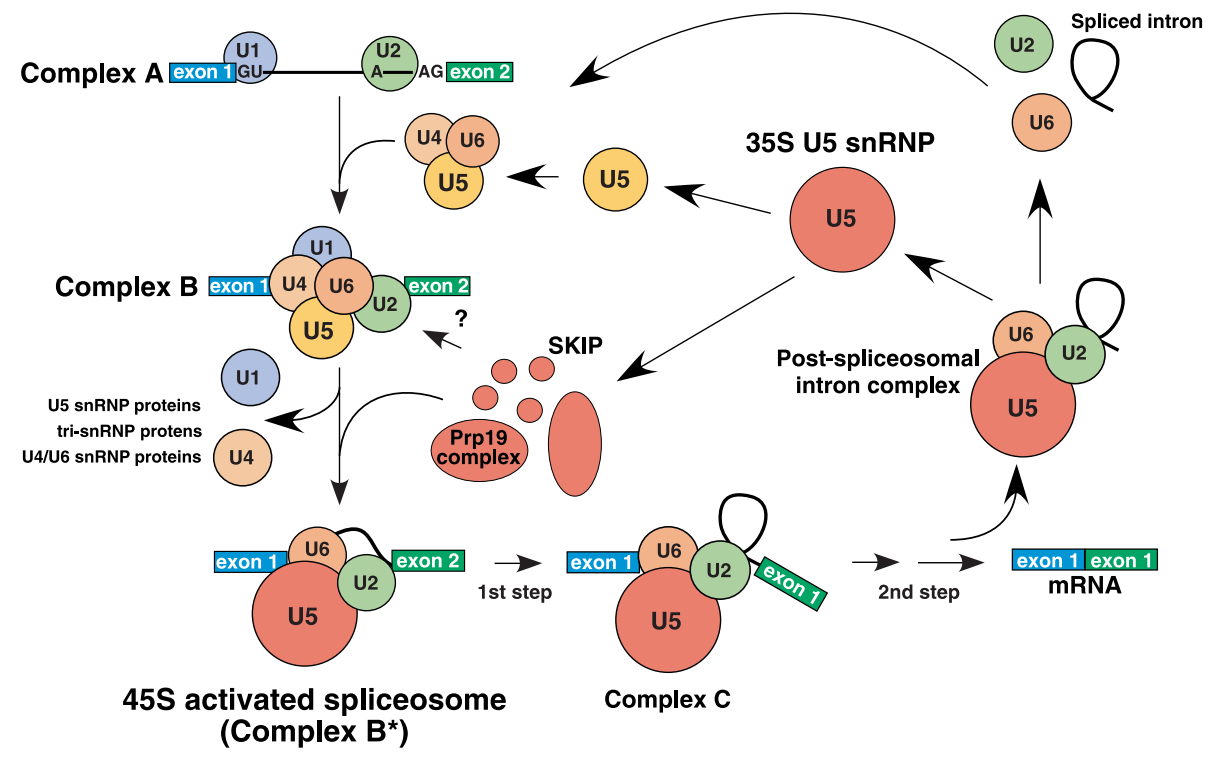

Fig. 4. Schematic diagram of spliceosomal and snRNP remodeling events. The color of the various snRNPs reflects the presence of the color-coded proteins shown in Fig. 3. Complexes with a red U5 snRNP contain the SKIP protein. plex B and then the activated spliceosome (complex B*). During the latter step, the U1 and U4 snRNPs, together with all U4/U6-specific, two tri-snRNP, and two U5-specific proteins, are destabilized or released. Some of the newly recruited proteins, including SKIP and the Prp19 complex, associate with the U5 snRNP, dramatically altering its composition. The restructured U5 complex persists without marked change in composition through both catalytic steps of splicing until it is released, initially together with U2 and U6 as part of the excised intron complex and then in the form of a $35 \mathrm{SU} 5$ particle. Before its reassociation with U4/U6 to form the U4/U6.U5 tri-snRNP, the $35 S$ U5 snRNP is converted into a $20 S$ particle. This conversion minimally entails the dissociation of the Prp19 complex and reassociation of the $102 \mathrm{~K}, 100 \mathrm{~K}$ and $15 \mathrm{~K}$ proteins. Whether the $35 \mathrm{~S}$ U5 is directly converted to a $20 \mathrm{~S}$ particle, or initially dissociates into an even smaller complex such as the recently described $16 S$ U5 particle observed in S. cerevisiae (18), is not clear and will be an interesting subject of future studies.

\section{References and Notes}

1. C. B. Burge, T. Tuschl, P. A. Sharp, in The RNA World, C. Gesteland, T Cech, F. Atkins, Eds. (Cold Spring Harbor Laboratory Press, Cold Spring Harbor, New York, ed. 2, 1999), pp. 525-560.

2. O. Gozani, J. G. Patton, R. Reed, EMBO J. 13, 3356 (1994).

3. M. Bennett, S. Michaud, J. Kingston, R. Reed, Genes Dev. 6, 1986 (1992)

4. J. Rappsilber, U. Ryder, A. I. Lamond, M. Mann, Genome Res. 12, 1231 (2002).

5. Z. Zhou, L. J. Licklider, S. P. Gygi, R. Reed, Nature 419, $182(2002)$

6. M. S. Jurica, L. J. Licklider, S. R. Gygi, N. Grigorieff, M. J. Moore, RNA 8, 426 (2002).

7. G. Neubauer et al., Nature Genet. 20, 46 (1998).

8. K. Hartmuth et al., in preparation.

9. M. Bach, G. Winkelmann, R. Lührmann, Proc. Natl. Acad. Sci. U.S.A. 86, 6038 (1989).

10. Materials and Methods are available as supporting online material at Science Online.

11. C. H. Chen et al., Nucleic Acids Res. 30, 1029 (2002).

12. M. D. Ohi et al., Mol. Cell. Biol. 22, 2011 (2002).

13. P. Ajuh et al., EMBO J. 19, 6569 (2000).

14. N. Kataoka, M. D. Diem, V. N. Kim, J. Yong, G. Dreyfuss, EMBO J. 20, 6424 (2001).

15. H. Le Hir, D. Gatfield, E. Izaurralde, M. J. Moore, EMBO J. 20, 4987 (2001).

16. C. L. Will et al., EMBO J. 21, 4978 (2002).

17. S. W. Stevens et al., Mol. Cell 9, 31 (2002).

18. A. Gottschalk, B. Kastner, R. Lührmann, P. Fabrizio, RNA 7, 1554 (2001).

19. We thank M. Raabe and G. Heyne for excellent technical assistance and P. Kempkes, T. Conrad, B. Hildebrandt, and H. Kohansel for preparing nuclear extract and UsnRNPs. We are grateful to B. Rhode for providing $\triangle \mathrm{U} 4 / \mathrm{U} 6 . \mathrm{U} 5$ extracts. This work was supported by grants from the Deutsche Forschungsgemeinschaft (SFB 523/A8) and the BMBF (031U215B) (to R.L.), and a grant from the Bundesministerium für Bildung, Wissenschaft, Forschung und Technologie (031U215A) (to M.W.).

Supporting Online Material

www.sciencemag.org/cgi/content/full/1077783/DC1

Table S1

Materials and Methods

27 August 2002; accepted 21 October 2002

Published online 21 October 2002;

10.1126/science. 1077783

Include this information when citing this paper. 